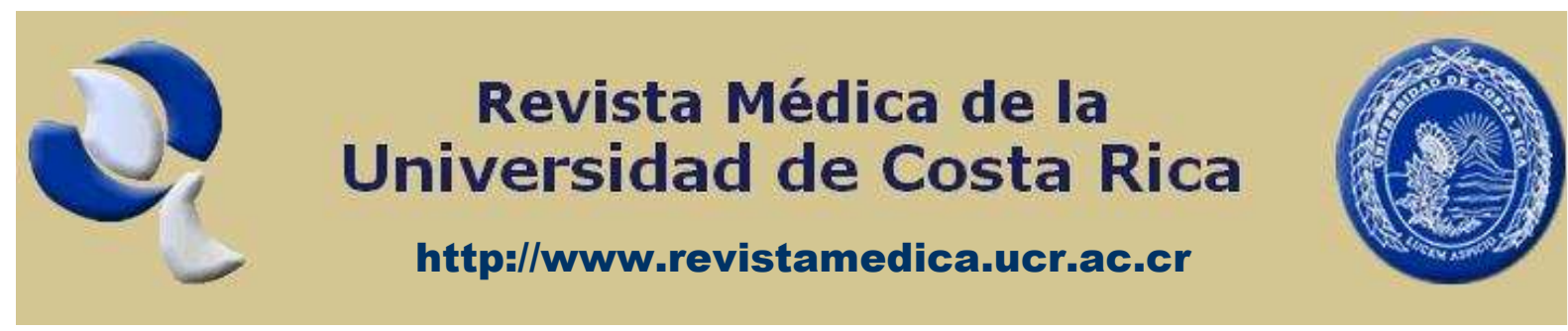

Caso clínico

\title{
CARCINOMA PIGMENTADO DE CÉluLAS ESCAMOSAS DE LA PIEL
}

\author{
Quirós, José Luis ${ }^{1}$; Rodríguez Segura, Karla ${ }^{2}$ y Pochet Sánchez, Luis ${ }^{2}$
}

1. Médico asistente especialista en Anatomía Patológica del Hospital Max Peralta de Cartago, Costa Rica, estudiante postgrado maestría en Ciencias Morfológicas; Universidad de Costa Rica, San Pedro, San José, Costa Rica. 2. Estudiante Universidad de Ciencias Médicas. UCIMED, San José, Costa Rica.

\begin{abstract}
Resumen
Se presenta el caso de un paciente masculino de 88 años quien presentó una lesión cutánea, de color oscuro, en la región malar izquierda. Por medio de una biopsia se determinó que consistía de un carcinoma de células escamosas pigmentado. Este tipo de tumor es inusual. Del $7 \%$ de los casos de cáncer de células escamosas solo el $0.01 \%$ presenta pigmento, lo que conlleva a realizar un diagnóstico diferencial con melanoma, un tumor cutáneo maligno de muy mal pronóstico.

Lo atractivo del caso es la descripción de un carcinoma epidermoide pigmentado que presenta una población acompañante de células positivas para los marcadores inmunohistoquímicos de HMB-45 y S-100, marcadores típicos del melanoma, lo que suele ser infrecuente.
\end{abstract}

Palabras claves: Cáncer de piel, Carcinoma epidermoide, Carcinoma de células escamosas, Melanoma, Inmunohistoquímica.

Recibido: Julio 2009. Aceptado: Septiembre 2009. Publicado: Septiembre 2009. 


\begin{abstract}
A case of a male patient of 88 years, who presents a skin dark color lesion in the left malar region. Through a biopsy determined that consisted of a pigmented squamous cell carcinoma. This type of tumor is unusual. $7 \%$ of cases of squamous cell cancer of only $0.01 \%$ had pigment, which leads to make differential diagnosis with melanoma, a malignant skin tumor with very poor prognosis.

The attraction of the event is the description of a squamous cell carcinoma that presents an accompanying population of cells positive for immunohistochemical markers of HMB-45 and S-100, typical markers of melanoma, a very infrequently case.
\end{abstract}

Key words: Cancer of skin(leather), Carcinoma epidermoide, Carcinoma of scaly cells, Melanoma, Inmunohistoquímica.

\author{
Abreviaturas \\ CCE: Carcinoma de células escamosas \\ CCEP: Carcinoma de células escamosas pigmentadas. \\ CBC: Carcinoma baso celulares. \\ CE: Cáncer epidermoide
}

\begin{abstract}
Abbreviations
CCS: Carcinoma of scaly cells

CCSP: Carcinoma of scaly pigmented cells.

CBC: Carcinoma base cellular.

CE: Cáncer epidermoide
\end{abstract}




\section{Introducción}

El cáncer de piel es un padecimiento que ha aumentado a nivel mundial [1]. En la población blanca esta enfermedad maligna es la más común [1] Existen dos tipos específicos de cáncer de piel que se dan con mayor frecuencia: el carcinoma basocelular y el carcinoma de células escamosas, los cuales se caracterizan por su capacidad infiltrante y baja tasa de metástasis [2].

\section{Caso Clínico}

Masculino de 88 años, vecino de Paraíso de Cartago, agricultor conocido portador de enfermedad de Parkinson, con enfermedad pulmonar obstructiva crónica, enfermedad cerebro vascular, e hipertensión arterial. Quien consulta por cuadro de 3 meses de evolución de lesión nodular ulcerada que mide $2 \times 1,8 \mathrm{~cm}$, localizada en la región malar izquierda, de color violáceo oscura, con presencia a nivel central de costra seudohemática. Se plantean como posibles diagnósticos: carcinoma epidermoide vs carcinoma basocelular, adicionalmente se describe en el examen físico queratosis actínicas múltiples. Se realiza biopsia insicional.

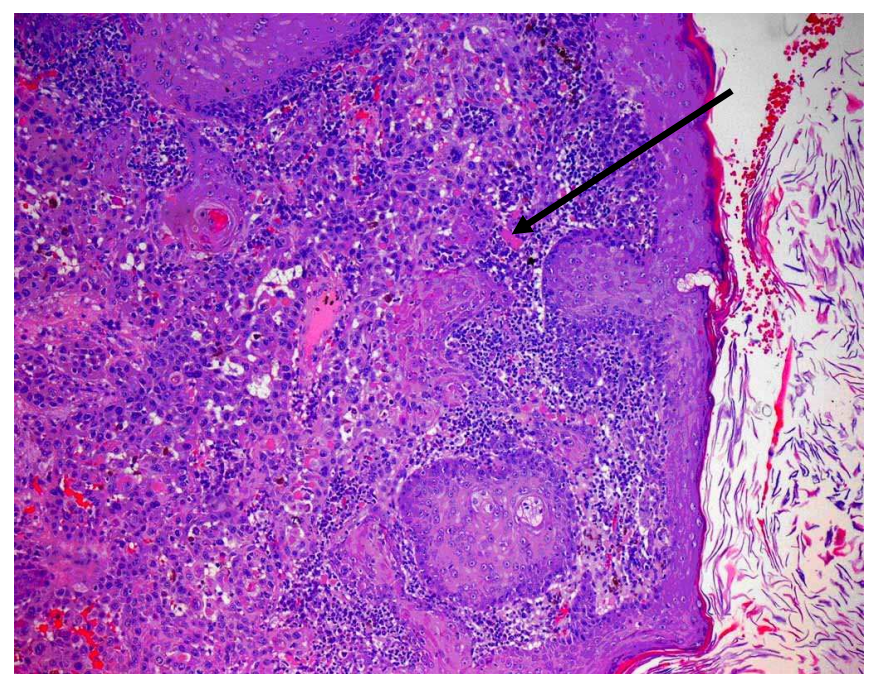

Figura 1. Microfotografía de piel con carcinoma epidermoide invasor. Tinción de Hematoxilina Eosina (10X).

\section{Discusión.}

En el presente caso se plantearon como diagnósticos diferenciales clínicos el carcinoma basocelular, carcinoma de células escamosas y melanoma.

El Carcinoma basocelular comienza como un nódulo perlado a veces con pequeños vasos telangiectásicos en su superficie de pequeño tamaño. El nódulo crece lentamente y puede experimentar ulceración central [2].

Existe una variante de carcinomas basocelulares que presentan pigmentación.

En el tumor puede haber cantidades variadas de melanina; los tumores con una acumulación más intensa se denominan CBC pigmentados. Aunque clínicamente no es más agresivo que un carcinoma basocelular que presente ulceración, el CBC pigmentado puede ser difícil de diagnosticar porque se confunde con un melanoma maligno [4].

La evolución natural del CBC es la de una neoplasia de crecimiento lento, infiltrante. El grado de destrucción local y el riesgo de recidiva varían según el tamaño, la duración, la localización del tumor, el subtipo histológico, la presencia de enfermedad recurrente y diversas características del paciente. La localización en la parte central de la cara (p. ej., nariz, pliegue nasolabial o zona peri orbitaria o peribucal), las orejas o el cuero cabelludo pueden indicar un riesgo mayor.

Los CBC nodulares, pigmentados, quísticos, o superficiales de pequeño tamaño responden bien a la mayoría de los tratamientos. Se ha cifrado el potencial de metástasis del CBC entre un 0.0028 y un $0.1 \%$ [3].

Mientras tanto el carcinoma de células escamosa es el tumor más frecuente de las zonas expuestas al sol en personas ancianas [5]. Su incidencia es superior en el sector femenino que en el masculino, a excepción de cuando se afectan las piernas [2] (ver figura 2). 
Factores que predisponen este tipo de cáncer, además de la luz solar son: carcinógenos industriales, úlceras crónicas, las osteomielitis con drenaje cutáneo, radiación ionizante e incluso ciertos hábitos como la masticación de tabaco [3].

La causa exógena más frecuente del CCE es la exposición a la luz ultravioleta con posteriores lesiones no reparadas del ADN [7].

La evolución natural del CCE depende de las características del tumor y del hospedador. Los tumores que surgen en una piel con lesiones actínicas poseen un potencial metastásico inferior a los de las superficies protegidas [8].

El potencial de metástasis de los CE originados en cicatrices de quemaduras, úlceras crónicas o genitales es más elevado [8]. La tasa global de metástasis en los tumores recurrentes puede aproximarse al 30\% [3].

Es frecuente que los tumores profundos, mal diferenciados, con infiltración del perineuro o de los vasos linfáticos se comporten de forma agresiva [3]. Los tumores múltiples de crecimiento rápido y conducta agresiva pueden constituir un reto terapéutico en los pacientes inmunodeprimidos [3]. El lugar más frecuente de metástasis son los ganglios linfáticos regionales. En este caso los pacientes presentan una tasa de supervivencia a los 5 años de $50 \%$ si solo hay adenopatía en un ganglio, entre 15-20\% cuando son varios los ganglios afectados (aproximadamente cuatro). También cabe la posibilidad de que este sea diseminado, donde la tasa de supervivencia sería menor, correspondiente a un 5\% en 5 años. [3].

Además de la piel, se pueden originar carcinomas de tipo epidermoide en otros tejidos tales como: cérvix uterino, vagina, pene, escroto, esófago, pulmón, laringe y boca.

Se debe nombrar también al melanoma, un tumor maligno de piel derivado de los melanocitos, las células que producen el color de la piel y dan el tono oscuro a los lunares [3].

En condiciones normales, los lunares son tumores benignos en la piel. Sin embargo, un lunar puede convertirse en un melanoma. Un lunar nuevo también puede ser un melanoma en fase inicial (6).

En Costa Rica los cánceres de piel por melanoma son menos comunes que los cánceres de piel por carcinoma (ver figura 2).

Figura 2: Incidencia por cáncer de piel melanoma y no melanoma para ambos sexos en Costa Rica 1995-2003.

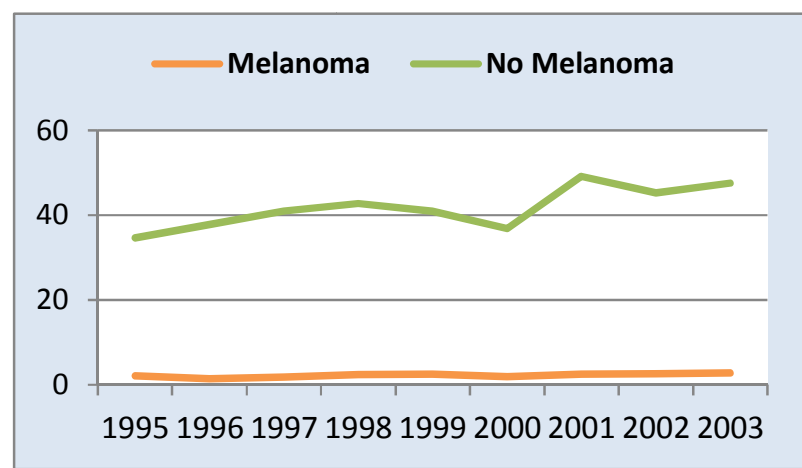

Fuente: M.Salud, Unidad de Estadística Registro Nacional de Tumores.

Modificada de: www.ministeriodesalud.go.cr

En cuanto a la incidencia de cáncer según el sexo, muestra que los hombres tienen mayor riesgo a padecer de esta enfermedad (ver figura $3)$.

Figura 3: Incidencia de cáncer de piel de acuerdo al sexo en Costa Rica 1995-2003.

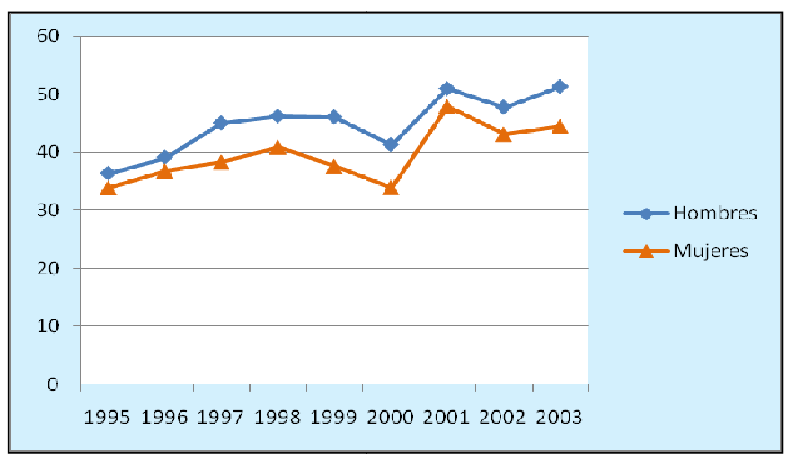

Fuente: M.Salud, Unidad de Estadística Registro Nacional de Tumores.

Modificada de: www.ministeriodesalud.go.cr 


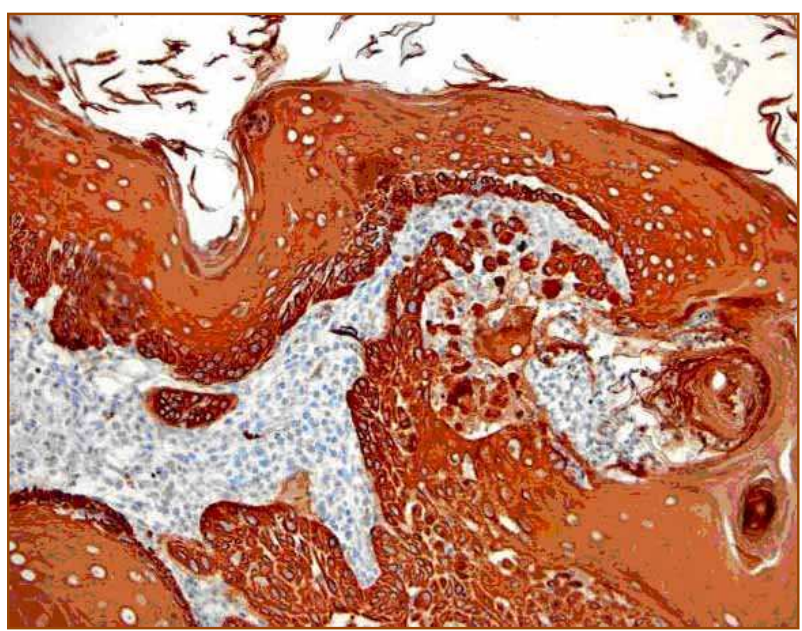

Figura 4. Microfotografía de piel con carcinoma epidermoide invasor. Tinción de Inmunohistoquímica para pancitoqueratina $(10 \mathrm{X})$.

La valoración histopatológica de la biopsia del presente caso mostro una neoplasia originada en la epidermis, constituida por células grandes, anaplásicas, de núcleos pleomórficos, con abundante citoplasma, con presencia de algunos puentes intercelulares, escasos rasgos de queratinización y abundantes figuras mitóticas atípicas. Las anteriores características apuntan hacia el diagnóstico de carcinoma de células escamosas moderadamente diferenciadas (Ver figura 1).

Sin embargo llamó la atención la presencia de una población de células dispersas en la neoplasia, que contienen un pigmento granular de color café. Esta ultima cualidad permite plantear la posibilidad de que la tumoración sea un melanoma. Se plantean como diagnósticos diferenciales

histopatológicos: Carcinoma de células escamosas vs Melanoma.

Al realizar estudios inmunohistoquimicos para las proteínas S-100, HMB-45 y pancitoqueratina se obtuvo que la mayoría de las células neoplásicas fueron positivas para la pancitoqueratina (ver figura 4) y negativa para los otros marcadores.

Sin embargo algunas de las células analizadas en la presente biopsia fueron positivas para S-100 y HMB-45 (ver figura 5 y 6).

El HMB-45 (ver figura 6) es una glicoproteína premelanosómica vinculada al sistema tirosinasa, es positivo en melanocitos "activados" y particularmente células de melanoma maligno [9]

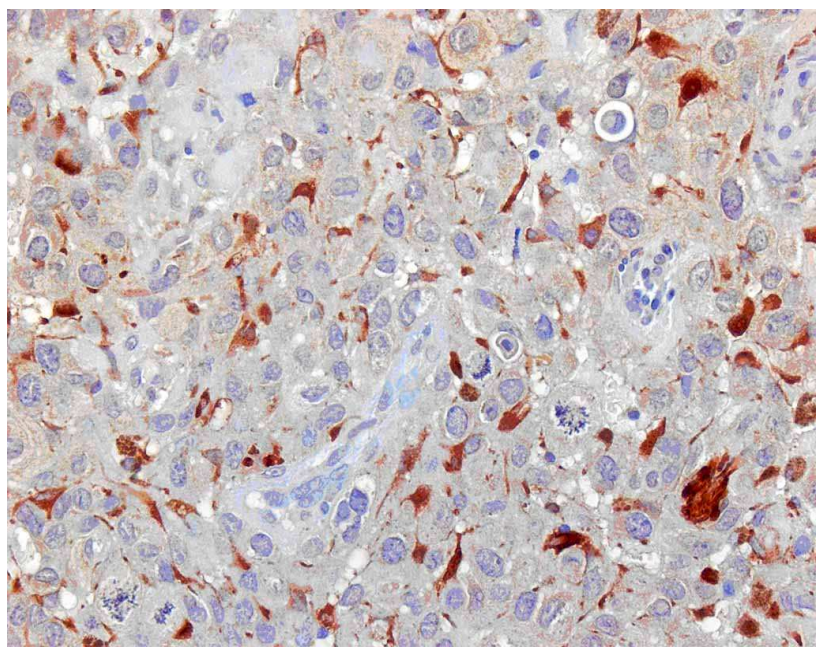

Figura 5 .Microfotografía de carcinoma de piel con tinción inmunohistoquímica para S-100. (Células positivas de color café)

La melanina se encuentra en las células epiteliales del tumor, así como en los macrófagos y células dendríticas [10]. Existen pocos casos reportados con estas características y aunque no parece afectar el pronóstico, se desconoce el comportamiento biológico de las células pigmentadas S 100+, HMB45 + que rodean a la neoplasia $[10,11,12]$. 


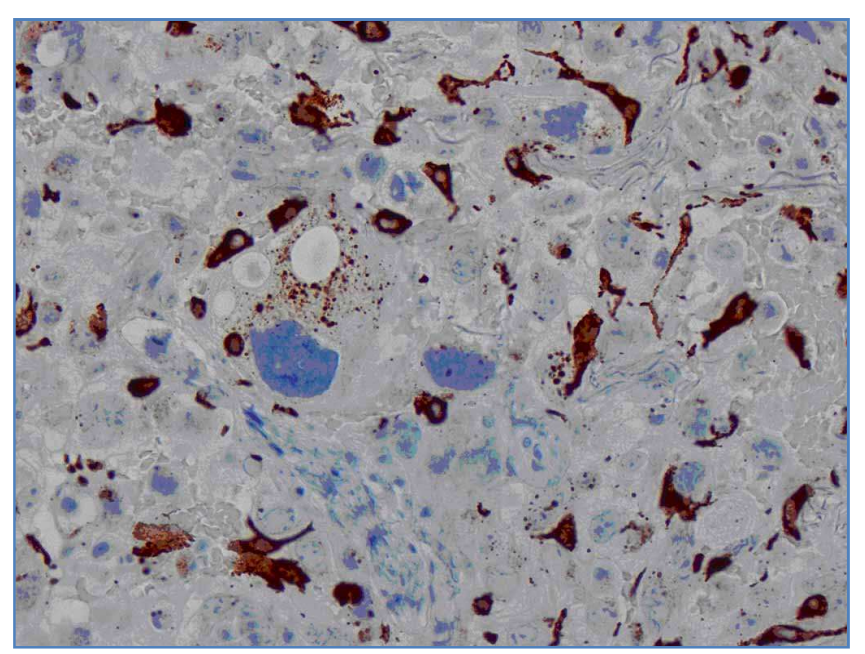

Figura 6 Microfotografía que muestra células positivas (color café) con tinción inmunohistoquímica HMB-45.

\section{Conclusiones}

Se diagnóstico el caso como un carcinoma de células escamosas pigmentado acompañada por células positivas a HMB-45 y S-100, alrededor de 30 casos han sido reportados en la literatura $[10,11,12,13]$ y es importante conocer su existencia para no confundirlo con melanoma ya que presentan diagnóstico y tratamiento diferentes.

Lo peculiar del caso es que estos dos marcadores dieran positivos, cuando en realidad se presenta un cáncer de células escamosas de la piel, el cual no debería tener melanina, y esto nos demuestra lo contrario.

\section{Referencias}

1. Ortiz Barboza Adolfo, Vargas Alvarado Rosa María, Muñoz Leiva Georgina. Incidencia y mortalidad del cáncer en Costa Rica 1990-2003. www.binasss.sa.cr/incidenciacancer.

Fecha de la publicación: Julio del 2005. Acceso: 7-Enero2009 10:00 am.

2. Kumar, Cotran, Robbins, Patología Humana, editorial Saunders, séptima edición, año 2004, Capítulo 22: La piel (pp. 801-807).
3. Braunwald, Fauci, Kasper, Hauser, Longo, Jameson, Harrison. Principios de Medicina Interna, editorial Mc Graw Hill, quinceava edición, año 2002, Capítulo 86: Melanoma y otros cánceres de piel.

4. Braunwald, Fauci, Kasper, Hauser, Longo, Jameson, Harrison: Principios de Medicina Interna, editorial Mc Graw Hill, quinceava edición, año 2002, Sexta parte: Oncología y Hematología (pp. 658).

5. E Wood Marie, Philips George, White Madeline, Hematology/ Oncology secrets, editorial Hanley \& Belfus, tercera edición, año2003, Cancer in the Elderly (pag165).

6. Ruiz Mateos Borja, Campos Pavón Jaime. AMIR MEDICINA, editorial Marbán, año 2007, Dermatología: Neoplasias cutáneas (pp.106-112).

7. LaRusso Laurie, MS, ELS. Carcinoma de Células Basales; Carcinoma de Células Escamosas.www.healthlibrary.epnet.com/GetContent. Fecha de publicación 2009. Acceso: 09-Julio-2009, 6:00 pm.

8. Instituto Nacional de Cáncer. Cáncer de piel, Tratamiento (PDQ) Versión profesional de salud.

www.cancer.gov Última actualización: 01-25-2008. Acceso: 09-Julio-2009, 6:25pm.

9. Casas. Patología de la fase nodular (vertical) del melanoma.

www.conganat.org/seap/reuniones/almagro2000/casas/ melanoma.htm Fecha de la publicación: Desconocida. Acceso: 22-Enero-2009, 11:15 pm.

10. K. Satter Elizabeth. Pigmented Squamous Cell Carcinoma. 2007; 29:486-489. Se cita en el Brief Report.

11. Terada T, Yamagami J, Fugimoto A, Tanaka K, Sugiura M. Pigmentado carcinoma de células escamosas de la piel de la mejilla, probablemente derivados de la queratosis solar. PMID: 12828613(PUBMED INDEX).

12. Jurado, Saez, Luelmo, Diaz, Mendez, Rey. Pigmented Squamous Cell Carcinoma of the Skin: Report of Two Cases and Review of the Literature. American Journal of Dermatopathology. 20(6):578-581, December 1998.

13. E Shirzadeh. Pigmented squamous cell carcinoma of the limbus area: A rare case. Indian J Ophthalmol > v.56(2); Mar-Apr 2008. 


\section{Correspondencia}

José Luis Quirós Alpizar

$\square$ email:dr.quiros@gmail.com

Karla Rodríguez Segura.

$\bowtie$ email: Karla_rs04@hotmail.com

Luis Pochet Sanchez

$\square$ email: leposa @hotmail.com 


\title{
PARA PUBLICAR EN LA REVISTA MÉDICA
}

\author{
DIRIJA SUS TRABAJOS A:
}

\author{
REV.MED.UCR@GMAIL.COM
}

